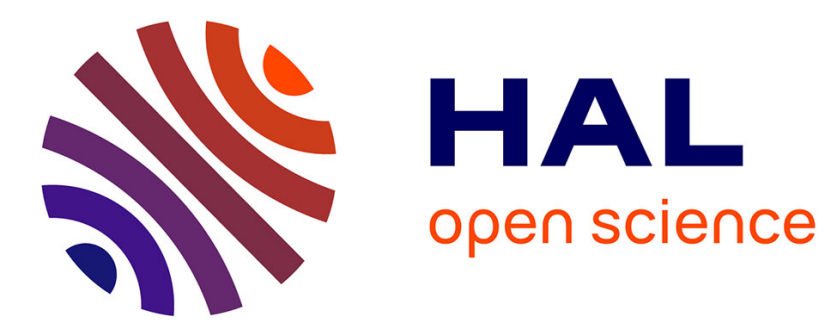

\title{
Comparative study of tools in drilling composites T700-M21 and T800-M21
}

John Le Dref, Florent Eyma, Gilles Dessein, Louis Etienne Denaud, Yann Landon

\section{- To cite this version:}

John Le Dref, Florent Eyma, Gilles Dessein, Louis Etienne Denaud, Yann Landon. Comparative study of tools in drilling composites T700-M21 and T800-M21. Advanced Materials Research, 2013, vol. 698, pp. 59-68. 10.4028/www.scientific.net/AMR.698.59 . hal-00944573

\section{HAL Id: hal-00944573 \\ https://hal.science/hal-00944573}

Submitted on 10 Feb 2014

HAL is a multi-disciplinary open access archive for the deposit and dissemination of scientific research documents, whether they are published or not. The documents may come from teaching and research institutions in France or abroad, or from public or private research centers.
L'archive ouverte pluridisciplinaire HAL, est destinée au dépôt et à la diffusion de documents scientifiques de niveau recherche, publiés ou non, émanant des établissements d'enseignement et de recherche français ou étrangers, des laboratoires publics ou privés. 


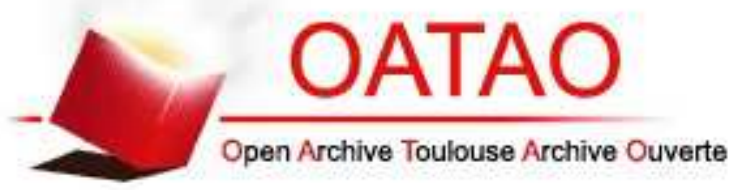

\section{Open Archive Toulouse Archive Ouverte (OATAO)}

OATAO is an open access repository that collects the work of Toulouse researchers and makes it freely available over the web where possible.

This is an author-deposited version published in: http://oatao.univ-toulouse.fr/ Eprints ID: 10700

To link to this article: DOI:10.4028/www.scientific.net/AMR.698.59 http://dx.doi.org/10.4028/www.scientific.net/AMR.698.59

\section{To cite this version:}

Le Dref, John and Eyma, Florent and Dessein, Gilles and Denaud, Louis Etienne and Landon, Yann Comparative study of tools in drilling composites T700-M21 and T800-M21. (2013) Advanced Materials Research, vol. 698 . pp. 59-68. ISSN 1662-8985 


\title{
Comparative study of tools in drilling composites T700-M21 and T800-M21
}

\author{
John LE DREF ${ }^{\dagger}$, Florent EYMA *, Gilles DESSEIN ${ }^{\dagger}$, \\ Louis-Etienne DENAUD ${ }^{\circ}$, Yann LANDON * \\ † Université de Toulouse, ENIT-INPT, Laboratoire Génie de Production, Tarbes, France \\ * Université de Toulouse, Institut Clément Ader, Tarbes, France \\ ${ }^{\circ}$ Centre Arts et Métiers ParisTech de Cluny, LABOMAP, Cluny, France
}

Keywords: Drilling, composite materials, thrust force, delamination, drill, mill, reamer

\begin{abstract}
The drilling of composite materials can produce, around the hole, defects and damages which decrease the mechanical resistance of the drilled workpiece. This study shows the influence of several tools (drill, mill and reamer) on the hole quality obtained, in the context of reference parts where surface integrity is a priority. An experimental study is suggested and the criteria used to assess the hole quality are defined. Results show the behavior of each type of cutting tool and their influence on the defects generated. Finally, this study helps creating a scale of recommended cutting conditions to reduce the tool wear and improve the hole quality.
\end{abstract}

\section{Introduction}

Composite materials carbon/epoxy are widely used in the aeronautical industry, as the T700-M21 and the T800-M21. They are mainly used on the primary and secondary structures as the wing box or the fuselage [1]. During the last stages to assemble the parts, drilling operations are necessary for bolts and rivets holes [2]. However, drilling composite materials can produce defects over the entry, the exit and the wall of the drilled hole. Those defects may then reduce the mechanical resistance of the workpiece $[3,4]$. It can be explained by the anisotropy of the material, made of several plies with different orientations $\left(0^{\circ}, \pm 45^{\circ}, 90^{\circ}\right)$. It also depends on the tool geometry and cutting conditions that alter the cutting mechanisms $[5,6]$. The impact of these specific defects on the mechanical behavior of the assembled pieces still is not well known. As a matter of fact, aeronautical structures are subject to high stresses and because of the need to insure security, design offices refuse the presence of any of those major defects, especially for standardized test pieces. Several works aims nowadays to understand the wear mechanisms and obtain workpiece free of any defect, which is difficult to obtain in the CFRP.

Among the principal types of cutting tools, the drills may generate delamination, at the entry and the exit of the hole. When entering the hole, the thrust force produced may imply the appearance of a crack that the peeling force will expand in a specific direction perpendicular to the tool axis. The propagation of the crack by the peeling force create a delamination that can go beyond the hole diameter [5]. The helix angle peel off the first ply while the cutting edge holds the ply below until it was cut, separating the two of them [3,7]. To sum up, the thrust force maintains the piece while the cutting face peels the first ply. All of contrary, at the exit hole, the thrust force create the delamination. While the uncut thickness decreases as the tool goes through the workpiece, the deformation resistance of the last plies decreases too. The thrust force becomes then more important than the bonding force between plies, hence causing delamination [4]. When a drill is used, cracks are initiated under the central part of the tool and may propagate under the cutting edge while the tool goes through. The last plies bend up under the thrust force and the delamination propagate beyond the hole diameter $[7,8]$.

Mills are often used to calibrate the final diameter of the hole after a pilot hole has been drilled [9, 10]. This method decreases the defects at the entry and exit of the hole. End mills are also used for drilling, the same way a drill is used. Reamers, used to calibrate the hole with a pilot hole, were the subject to only a few previous studies [9, 10]. The use of this kind of specific tools and the best choice of cutting conditions, when drilling, may reduce or nullify delamination [11]. 
Whatever cutting conditions were chosen, several works $[7,12,13]$ demonstrated that an increase of the feed rate and the cutting speed induce an increase of the defects in the hole. However, few studies aims at the characterization of the hole quality, which impacts the mechanical resistance, for a large range of cutting speed and feed rate.

This paper suggest optimal cutting conditions for those three types of tools (drill, mill, reamer), for hole diameter of $4.8 \mathrm{~mm}, 6.35 \mathrm{~mm}$ and $12.7 \mathrm{~mm}$, and for workpiece thicknesses of $4 \mathrm{~mm}$ and $8 \mathrm{~mm}$. Defects generated during drilling are quantified and analyzed according to the integrity criteria of the workpiece material.

\section{Materials}

\subsection{Workpiece materials and machine used}

The composite materials T700-M21 and T800-M21 are laminates reinforced with carbon fibres (T700 or T800) within a thermosetting resin made of epoxy M21. The tested workpiece dimensions are $175 \mathrm{~mm} \times 40 \mathrm{~mm}$ and, of 4 or $8 \mathrm{~mm}$ thick. The unidirectional plies are orientated as follows:

- $\left[0^{\circ}, 45^{\circ}, 90^{\circ},-45^{\circ}\right]_{2, \mathrm{~S}}$ (thickness $4 \mathrm{~mm}$ ).

- $\left[0^{\circ}, 45^{\circ}, 90^{\circ},-45^{\circ}\right]_{4, \mathrm{~S}}$ (thickness $8 \mathrm{~mm}$ ).

The CNC machine used in this study is a vertical 5-axis milling center. The spindle has magnetic bearings and can reach a rotating speed of $40000 \mathrm{rpm}$. It is possible to measure the cutting forces during the operation by measuring the current consumed by the magnetic bearings with a precision below $5 \mathrm{~N}$. An in-depth study would be needed for more precision, but is not needed here. This indirect method only offers an estimation of the cutting forces, which is sufficient to compare delamination and tool wear.

\subsection{Cutting tools}

Eight different tungsten carbide-based tools (Figure 1) are tested in this study. As discussed in the following papers $[2,5,13]$, it is the best compromise between cutting ability and tool wear. Actually, diamond-based tools are more efficient and achieve a better hole quality, however, because the first ones are cheaper, they offer a better solution to the companies and their subcontractors. As advised by the previous studies, experiments focus on the drills and mills that are supposed to be the most efficient and the most adapted tools for the drilling of carbon reinforced laminates. Reaming operation is necessary to obtain the hole quality requested by the engineering office. From an economical point of view, it would be best to drill a hole in one operation. A reaming operation is time-consuming, hence adding a cost. Manufacturers wish to avoid this operation but it is still mandatory for the hole quality. The tools tested (table 1) are plugged by heat shrinking in the spindle to offer optimal coaxiality (coaxiality misalignment below $5 \mu \mathrm{m}$ ).

Table 1 : Tested tools presentation

\begin{tabular}{|l|c|c|l|}
\hline \multicolumn{1}{|c|}{ Type of tool } & Tool diameter(mm) & Hole diameter $(\mathbf{m m})$ & \multicolumn{1}{|c|}{ Comments } \\
\hline Tool 1 : Mill & 4 & 4.8 & End mill - 3 teeth \\
\hline Tool 2 : Drill & 4.5 & 4.5 & 2 teeth \\
\hline Tool 3 : Reamer & 4.8 & 4.8 & 6 teeth \\
\hline $\begin{array}{l}\text { Tool 4 : Alternating tooth mill } \\
\text { grain cutter }\end{array}$ & 6 & 6 & End mill - 2 teeth \\
\hline Tool 5 : Reamer & 6.35 & 6.35 & 6 teeth \\
\hline Tool 6 : Drill & 12 & 12 & 2 teeth \\
\hline $\begin{array}{l}\text { Tool 7 : Alternating tooth mill } \\
\text { grain cutter }\end{array}$ & 12 & 12 & End mill - 2 teeth \\
\hline Tool 8: Alternating tooth mill & 6 & 12.7 & \\
\hline
\end{tabular}




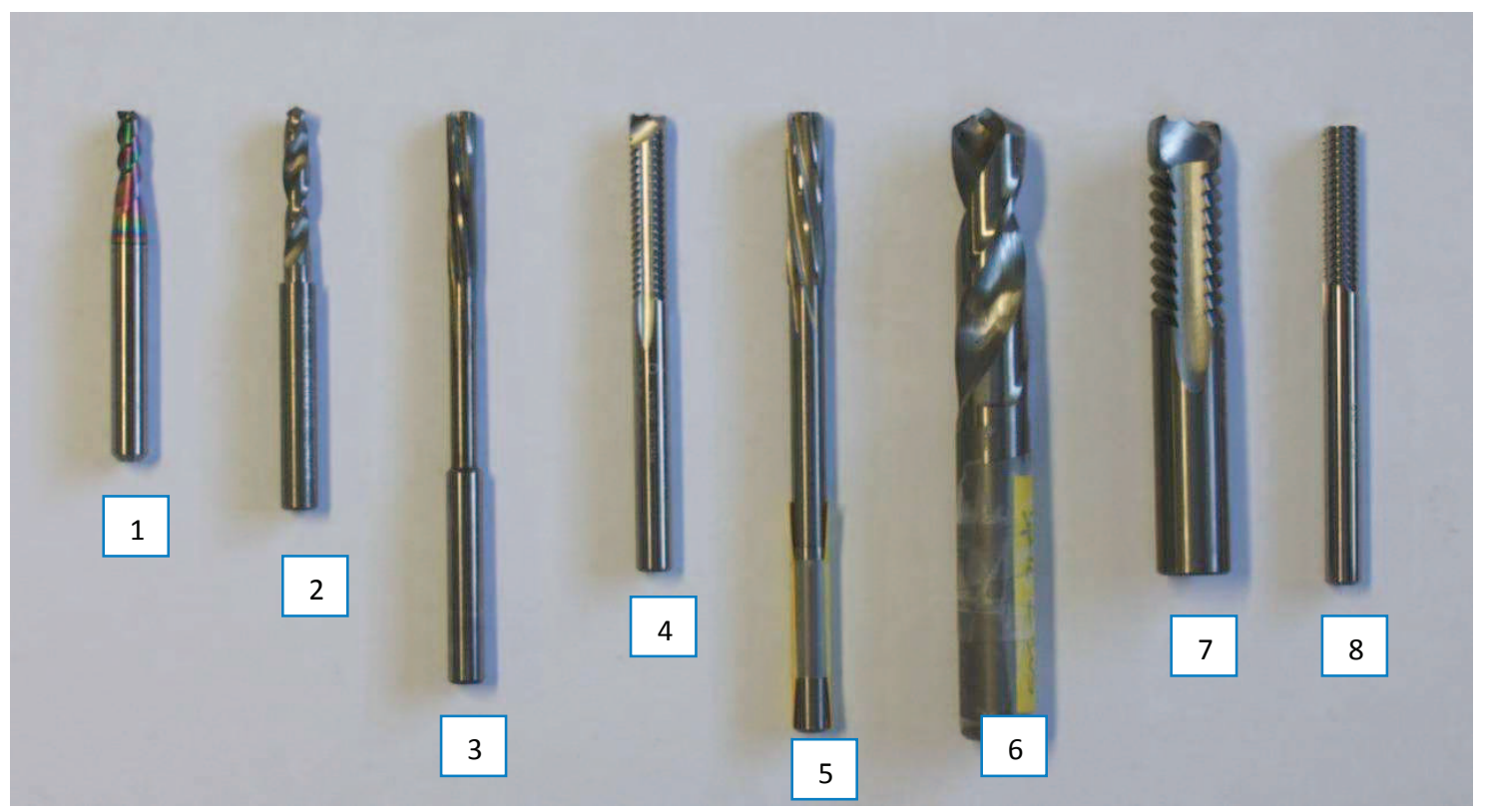

Figure 1 : Cutting tools

\section{Experimental procedures}

A design of experiments has been used to study each tool. Two factors (cutting speed and feed rate) and five levels are studied. The workpieces are clamped on a plate of aluminum alloy to avoid disturbance due to poor positioning, with splinterguard previously machined. It limits the delamination of the last ply to the diameter of the splinterguard. This hole is a bit larger than the hole diameter to avoid the testing plate machining and the chips going through the hole leaving defects on the wall.

\subsection{Choice of the cutting conditions}

The cutting speed values have been chosen within the range of $\left[\mathrm{Vc}_{\min } ; \mathrm{Vc}_{\mathrm{max}}\right]\left(\mathrm{Vc}_{4}-\mathrm{Vc}_{0}\right.$ in Figure 2) and the increment Un, as follows:

$$
V c_{\max }-V c_{\min }=\sum_{0}^{3} 1.2^{n} U_{0} \quad \text { and } \quad U_{n+1}=1.2 U_{n} \quad \text { for } \mathrm{n}=(0,1,2)
$$

The mathematical expression of the cutting speed for the experiments $\mathrm{n}+1$ becomes:

$$
V c_{n+1}=\sum_{0}^{n} U_{n}+V c_{0} \text { for } \mathrm{n}=(0,1,2,3)
$$

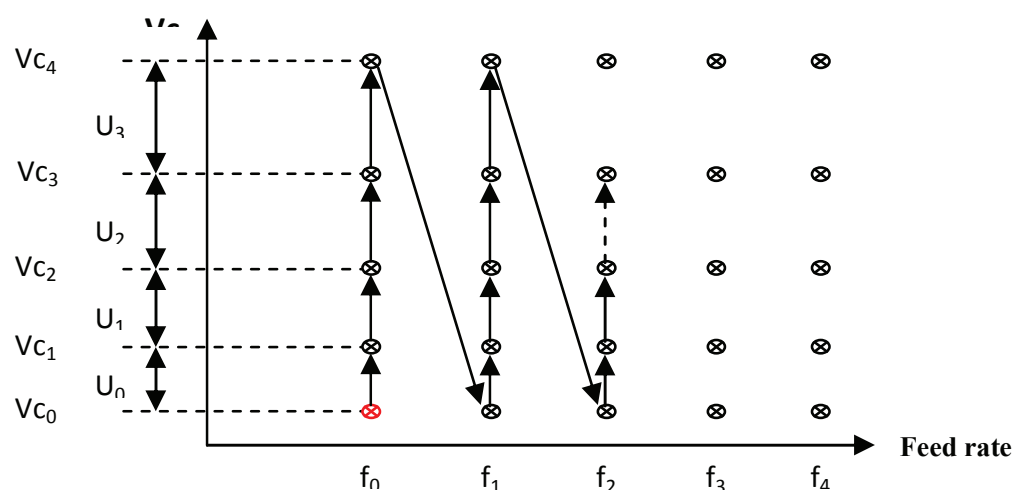

Figure 2 : Illustration of the cutting conditions tested

This method allows to test the range of cutting speeds chosen $\left[\mathrm{Vc}_{\min } ; \mathrm{Vc}_{\mathrm{max}}\right]$, with a geometrical factor of 1.2 from the initial speed $\mathrm{Vc}_{0}$. This speed is the one recommended by the tool manufacturer to machine carbon-based composites. By this mean, the firsts tests will be performed with speeds close to the one recommended when the next ones will be used to test larger speeds. The increment of feed rate between each level is constant and is calculated as $\left(f_{\max }-f_{\min }\right) / 5$ to keep consistent values. 
Table 2 : Tools and associated cutting conditions

\begin{tabular}{|c|c|c|c|c|c|}
\hline \multirow{2}{*}{ Tool } & \multicolumn{2}{|c|}{$\mathbf{V c}(\mathbf{m} / \mathbf{m i n})$} & $\mathbf{U}_{\mathbf{0}}$ & \multicolumn{2}{|c|}{$\mathbf{f}(\mathbf{m m} / \mathbf{t r})$} \\
\cline { 2 - 6 } & $\mathbf{m i n}$ & $\mathbf{m a x}$ & & $\mathbf{m i n}$ & $\mathbf{m a x}$ \\
\hline Tool 1 : Mill & 100 & 300 & 37.3 & 0,06 & 0,18 \\
\hline Tool 2 : Drill & 70 & 400 & 61.5 & 0.01 & 0.05 \\
\hline Tool 3 : Reamer & 20 & 100 & 14.9 & 0.15 & 0.35 \\
\hline Tool 4 : Alternating tooth mill grain cutter & 90 & 500 & 76.4 & 0.015 & 0.135 \\
\hline Tool 5 : Reamer & 20 & 150 & 24.2 & 0.2 & 0.5 \\
\hline Tool 6 : Drill & 70 & 800 & 136.0 & 0.08 & 0.18 \\
\hline Tool 7 : Alternating tooth mill grain cutter & 70 & 350 & 52.2 & 0.06 & 0.15 \\
\hline Tool 8 : Alternating tooth mill & 100 & 500 & 74.5 & 0,06 & 0,30 \\
\hline
\end{tabular}

The table 2 shows the cutting conditions tested for each tool. The lower values follow the recommendations of the tool manufacturers while the maximal values have been chosen from previous studies and the limits of the machines $[4,6,10]$.

\subsection{Measured criteria}

Several criteria have been used to characterize the hole quality of the workpiece. Measures using a camera USB 90x have also been done to quantify the defects at the entry and the exit of the hole:

- The surface of the defect, called $S_{\max }$, on Figure 3(a), correspond to the area (in $\mathrm{mm}^{2}$ ) of the damaged part (splintering, delamination...) after drilling of the first ply (entry) or the last ply (exit).

- The orientation of the defect on Figure 3(b), is the angle $\alpha_{1}$. This angle is measured between the point of the hole where is found the maximal defect, and the orientation of the fibers of the first ply.

- The size of the defect, noted $\varnothing_{\max }$ on Figure 3(a), is the diameter corresponding to the maximal defect.
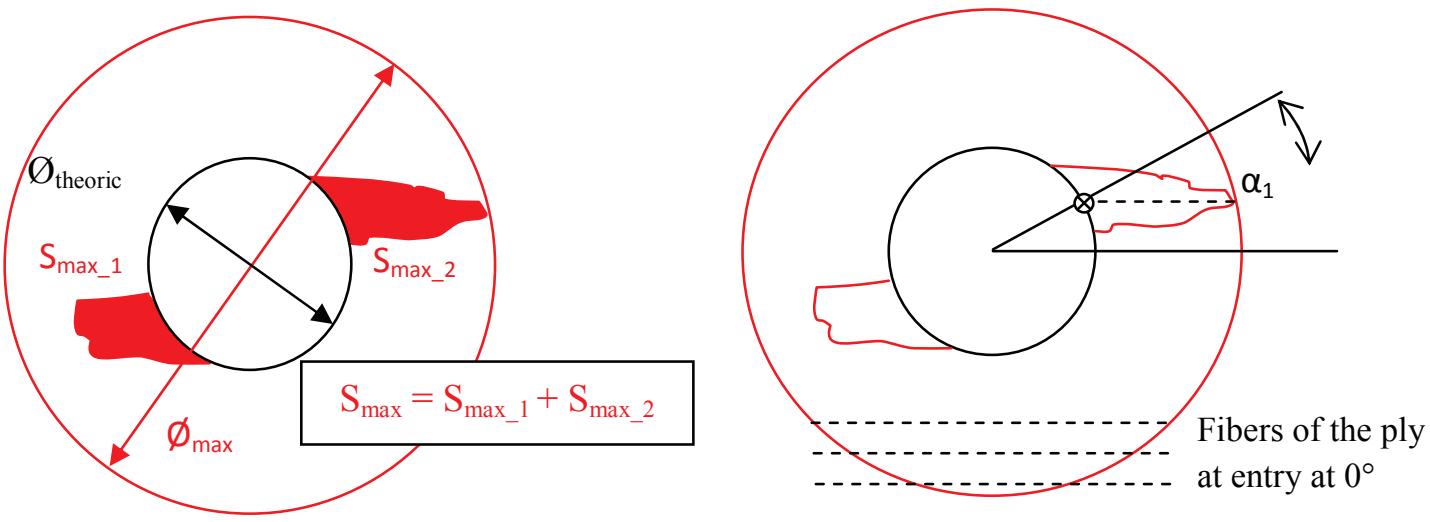

Figure 3 : Surface, size (a), and orientation (b) of the delamination defect

In this study, two criteria were used to define the maximal acceptable defect:

- The criterion "zero defect" :

- For a roughing operation, this criterion means that the size of the defects $\left(\varnothing_{\max }\right)$ is smaller than the hole diameter to be drilled in the finishing operation $\left(\varnothing_{\text {finishing }}\right)$,

- In the case of a finishing operation, this criterion means $\emptyset_{\max } \leq\left(\varnothing_{\text {finishing }}+x\right)$, with $x$ equal to $0.2 \mathrm{~mm}$ for the diameter $4.8 \mathrm{~mm}$, and $\mathrm{x}$ equal to $0.3 \mathrm{~mm}$ for the drilled diameters $6.35 \mathrm{~mm}$ et $12.7 \mathrm{~mm}$. $x$ represents the defect acceptable and is chosen with the agreement of the industrial partner.

- The criterion " $\varnothing_{\text {countersink }}$ " is used when the drilling or milling operation is followed by a countersinking operation. In this case, the acceptable diameter of the defect has to be lower than the countersink diameter. 
The surface roughness has been measured on a surface of the hole wall. Because the laminates are anisotropic, the measure by contact of the roughness is at the same time heavily depending on the trajectory of the pin and on the orientation of the ply [12]. To analyze the surface roughness obtained, several measures have been done on different generating lines of the wall. The conclusion is that the measures will be done on $45^{\circ}$ sector, keeping the criterion of surface roughness Ra.

As the thrust force measured is function of the cutting conditions applied and have a consequence on the defects, it is possible to correlate the cutting conditions to the hole quality, by anticipating the forces. The measurement of the force shows three stages (figure 4):

1-The penetration of the tool in the workpiece implies an increase of the thrust force. If the increase is non-linear, it may suggest a delamination or a splintering at the hole entry. 2-Once the tool entirely entered the workpiece and until the tip goes through the last ply, the thrust force is considered constant. Tool wear may slightly increase the cutting forces in this zone but it is neglected as the tool drills on a few millimeters. The increase of the surface of contact between the wall and the tool at the margin edge is also neglected, because it has little influence on the thrust force.

3-The output of the tool tip is accompanied by a decrease in the thrust force with the same

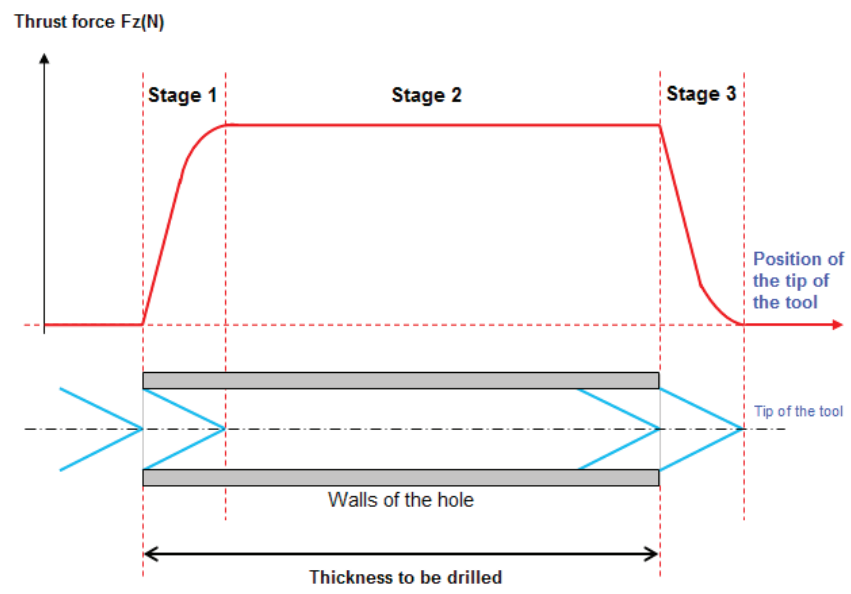

Figure 4: Three stages of measured forces perturbations as in step 1 .

\section{Analysis of the results}

\subsection{The mills}

The first three mills ( ${ }^{\circ} 1,4$ and 7 on Figure 1 ) have been used for the drilling of holes while the last one $\left(\mathrm{n}^{\circ} 8\right)$ has been used for contouring in a finishing operation.

When drilling, the splintering surface on the face of hole entry increases with the feed rate. In contrast, it did not depend much on the cutting speed. Both those cutting conditions did not affect the orientation of the defect. However, it is proven that the defect is maximum in the area of « compression + bending " of the fibers (Figure 6). The greater the feed rate is, the more the tool pushes the material of the workpiece, increasing the thrust force. A relation of proportionality has been observed between the increase of the thrust force and the increase of the feed rate from previous study and on those results $([7,10]$ and Figure $)$. It is particularly interesting to note the evolution of cutting forces with the evolution of the cutting speed, which demonstrates that the experimental approach used is necessary and that a study based on the inflection of the specific energy cutting does not guarantee sustainable results. 

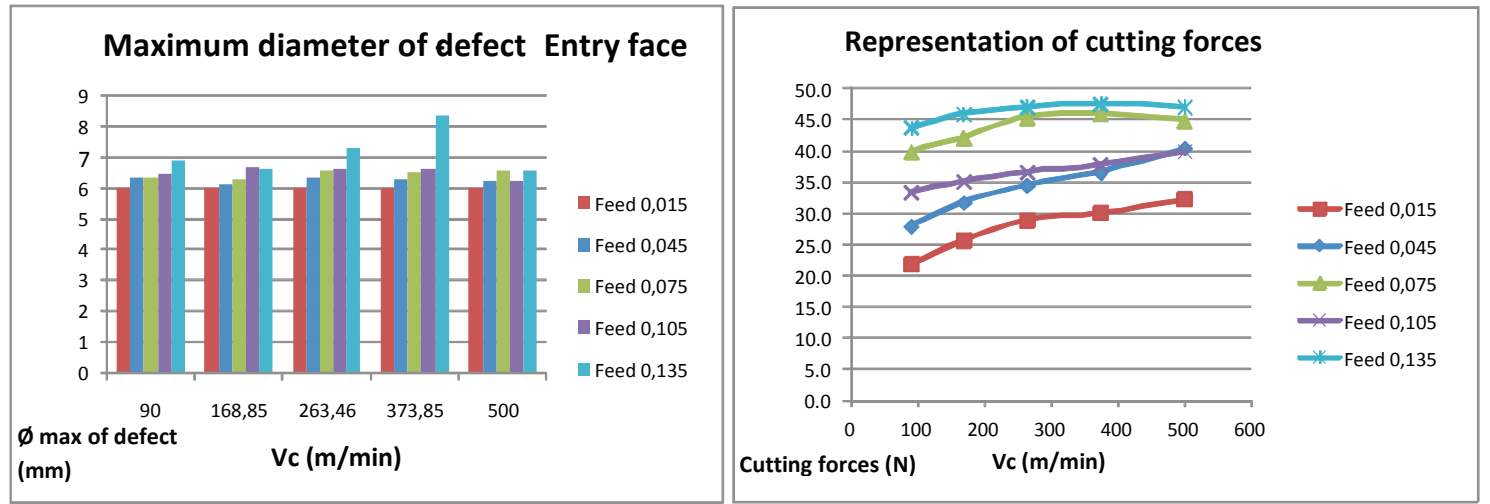

Figure 5 : Relations cutting conditions - diameter of defect - thrust force (tool 4)
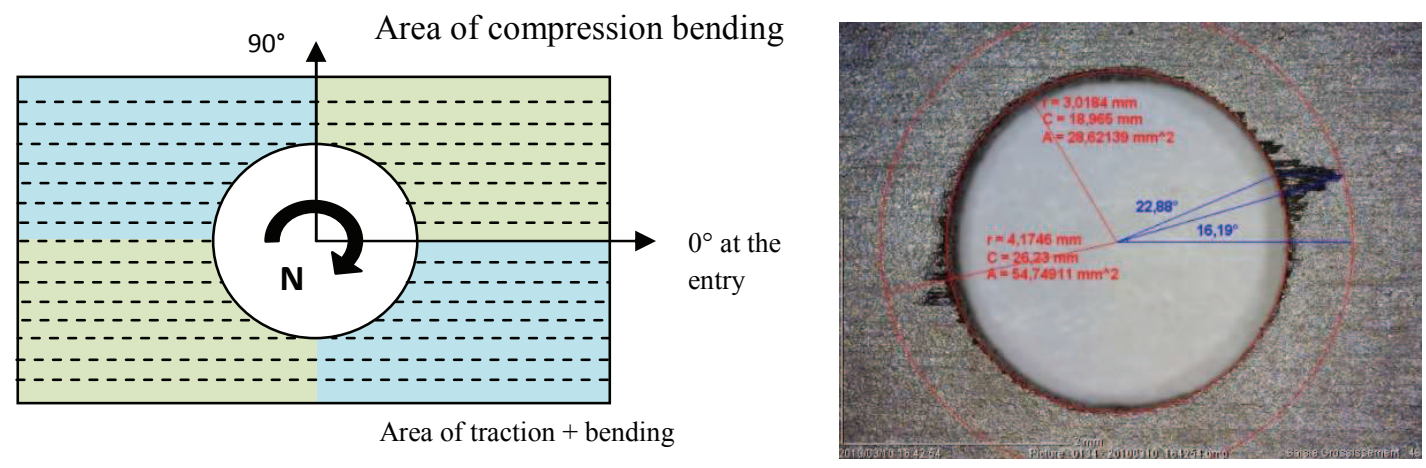

Figure $6:$ Tool actions on the fibers and splintering

The main criterion chosen is the size of the defect on the surface of entry or exit. The results can be used by companies, to choose the most efficient couple of cutting conditions. A few conclusions can be done. The drilling using the mill of diameter $6 \mathrm{~mm}$ (tool 4) shows that, for any cutting speed under $500 \mathrm{~m} / \mathrm{min}$, for the low feed rates of $0.015 \mathrm{~mm} / \mathrm{rev}$ or $0.045 \mathrm{~mm} / \mathrm{rev}$, the drilled hole presented no detectable defect. However, with a greater feed rate faster than $0.075 \mathrm{~mm} / \mathrm{rev}$, higher cutting speeds could cause the apparition of delamination greater than the acceptable size. This limit was the diameter of the contouring finishing operation, which is $\varnothing 6.35 \mathrm{~mm}$. If the criterion " $\varnothing_{\text {countersink }}$ " was chosen, those holes would be generally acceptable on a larger range of cutting speeds and feed rates.

The $\varnothing 12 \mathrm{~mm}$ mill (tool 7) generated defects at the entry for any cutting conditions. But those defects were small enough, below the contouring diameter $(\varnothing 12.7 \mathrm{~mm})$ for feed rates under $0.06 \mathrm{~mm} / \mathrm{rev}$. The range for feed rates that generate acceptable defects is then limited. However, the cutting speed can be multiplied by 5 (to $350 \mathrm{~m} / \mathrm{min}$ ) without degrading furthermore the workpiece. Once more, the criterion « $\emptyset_{\text {countersink }}$ " allows a greater range of cutting conditions respecting the condition of size: all feed rates were acceptable.

For the tool $1(\varnothing 4 \mathrm{~mm})$, the defects were always larger than the contouring diameter $(\varnothing 4.8 \mathrm{~mm})$ but they were still under the countersinking size. The inacceptable size of the defects can be linked to the fact that this tool wears rapidly during the drillings. It may not be appropriate for the cutting of composites.

The mill of diameter $6 \mathrm{~mm}$ is also used for contouring (tool 8) on its profile with alternating tooth to obtain the diameter $12.7 \mathrm{~mm}$. Good results were obtained since the hole has no surface defect when the feed rate is still below $0.06 \mathrm{~mm} / \mathrm{rev}$ and for any cutting speed, or for any feed rate and a cutting speed under $100 \mathrm{~m} / \mathrm{min}$.

Finally, among the four mills studied, only the tool 1 is denied. The three other tools with alternating tooth seem particularly adapted. This confirms that the type of tool teeth is a main characteristic to look for when choosing a cutting tool for this kind of material. 


\subsection{The drills}

Drills studied are tool 2 and tool $6(\varnothing 4.5$ and $\varnothing 12 \mathrm{~mm})$. The conclusions concerning the influence of the cutting conditions are the same, compared to the mills: the defects on the surface and the thrust force are mainly influenced by feed rate and slightly by the cutting speed chosen (Figure 7).
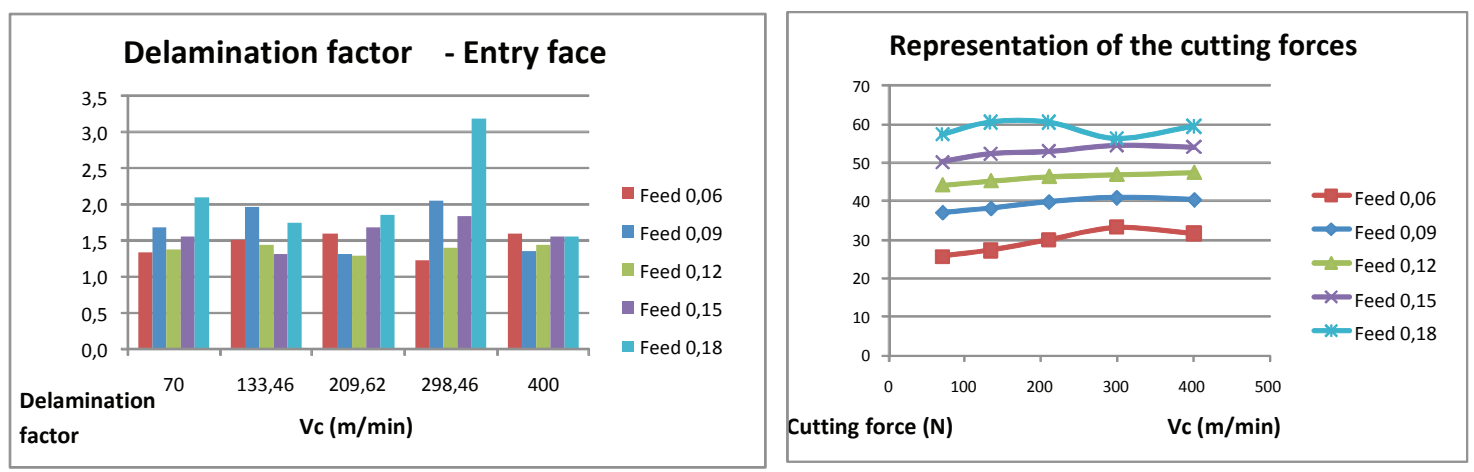

Figure 7 : Relations cutting conditions - forces - defects (tool 2)
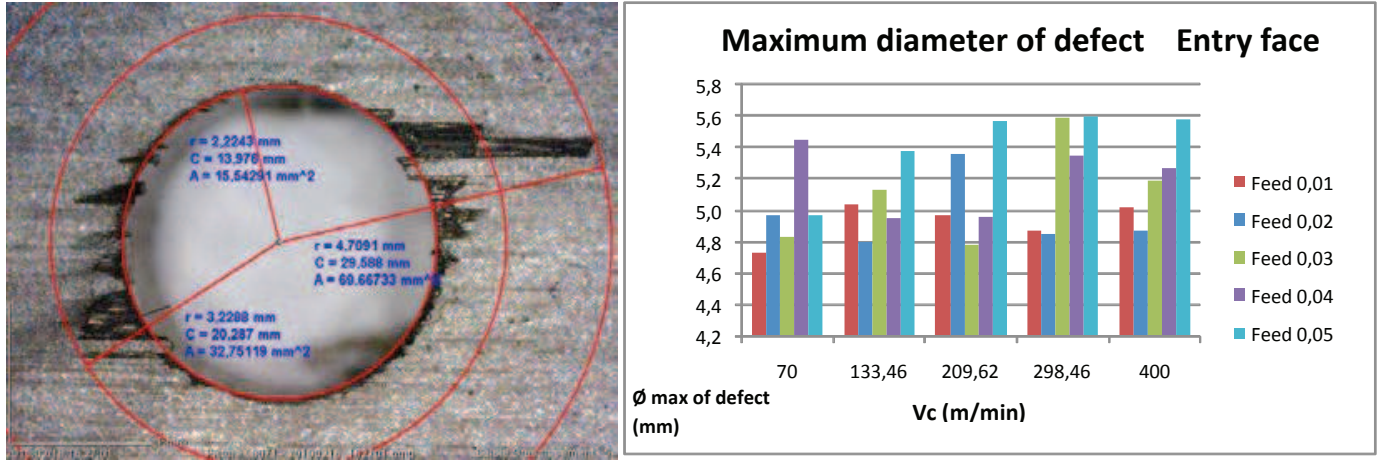

Figure 8 : Example of splintering (tool 2, T800, $\mathrm{Vc}=70$ et $\mathrm{f}=0.01$ ) and $\emptyset_{\max }$

To sum up about all the drills tested, the cutting conditions recommended by the tool manufacturers are too high to ensure a hole quality respecting the chosen criteria. For the tool 2, the feed rate of $0.06 \mathrm{~mm} / \mathrm{rev}$ initially recommended has to be reduced to $0.01 \mathrm{~mm} / \mathrm{rev}$ to limit the damages (Figure ). With this tool and this feed rate, only a cutting speed below $70 \mathrm{~m} / \mathrm{min}$ offers a size of defect under the threshold of the contouring diameter $4.8 \mathrm{~mm}$.

The drill of diameter $12 \mathrm{~mm}$ (tool 6), despite the reduction of the feed rate from $0.12 \mathrm{~mm} / \mathrm{rev}$ to $0.08 \mathrm{~mm} / \mathrm{rev}$, does not produce any acceptable hole. This drill was then denied of the machining strategy and has been replaced by the mill of diameter $12 \mathrm{~mm}$

It can be seen in any way that it is difficult to satisfy the criterion $\varnothing_{\max }<\varnothing_{\text {finishing. Although those }}$ drills are often used by the industry, this study shows that the mills with external tips (alternating tooth mill grain cutter, tools 4 and 7), when drilling or contouring, are more efficient and offers holes with a better quality. The geometry of those mills makes it easier to cut the fibers, and get a better surface roughness while reducing the thrust force created. Moreover, among the three types of tools, the mills may drill with the highest cutting speeds and feed rates without an increase of tool wear. Tool 2 (drill Ø4.5) wear can be directly correlated with the criterion $\emptyset_{\max }$ (Figure 9). This type of results may tell that it is possible to pilot the tool life with the help of the quality hole obtained, as well as to monitor the thrust forces measured while drilling to determine the time when the tool has to be changed. 


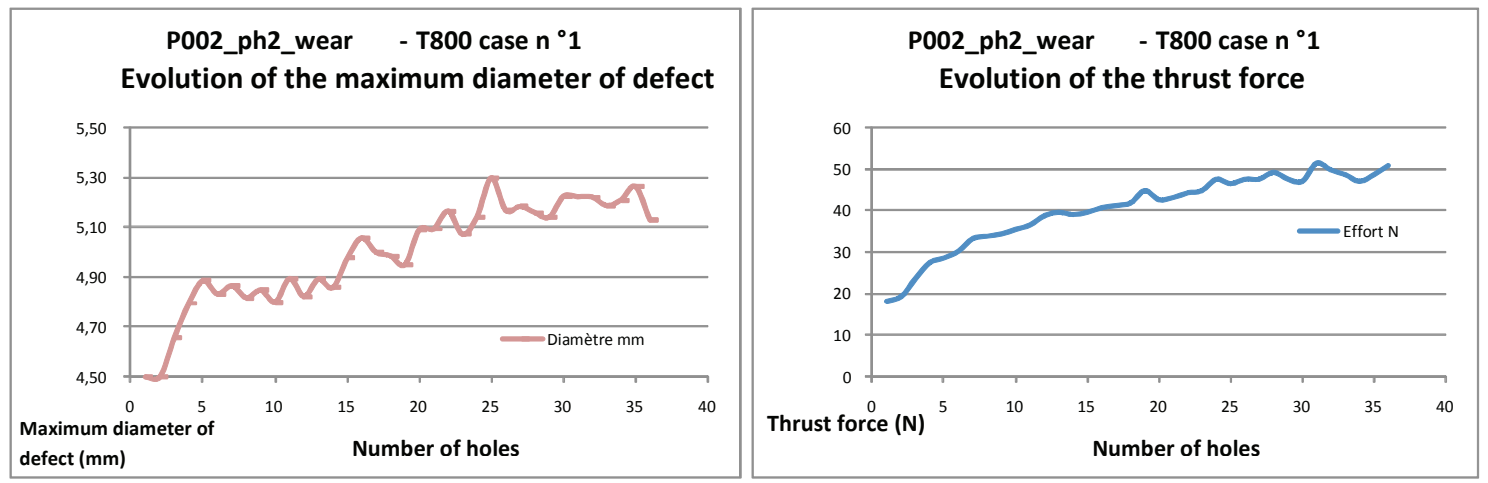

Figure 9 : Relation between defect and thrst force (tool 2, $\mathrm{Vc}=70$ et $\mathrm{f}=0.01$ )

The previous work of P. Rahmé [8] can corroborate those results. The model of the damages found on the laminates drilled is based on the hypothesis that the defect on surface appears when the thrust force reaches a critic value. This value is defined by the fracture toughness of the material in a mode I cracking. For instance, considering a helicoidal drill, the critical thrust force $\mathrm{F}_{\mathrm{A}}$ is:

$$
F_{A}=\pi \cdot \sqrt{\frac{8 \cdot G_{I C} \cdot E \cdot h^{3}}{3 \cdot\left(1-v^{2}\right)}}
$$

Figure compares the ration of the thrust force generated by each tool to the critical thrust force (Fi/ $\mathrm{F}_{\mathrm{A}}$ ) as a function of the ratio of the defect diameter to the tool diameter $(\mathrm{s}=\mathrm{c} / \mathrm{a})$. A high ratio of forces, greater than 1, means the critical force has been exceeded while a great ratio of diameters means the defects is larger. This graph shows that alternating tooth mill (noted Saw drill on figure 10), which are the mills $n^{\circ} 4$ and 7 , are the most efficient when it comes to the defect encountered at the entry of the hole. It can be explained by the external repartition of the thrust force on the tool tips. When using a conventional drill, the thrust force is mainly generated by the central part of the tool, and can reach $50 \%$ of the total thrust force of the tool on the material. [8].

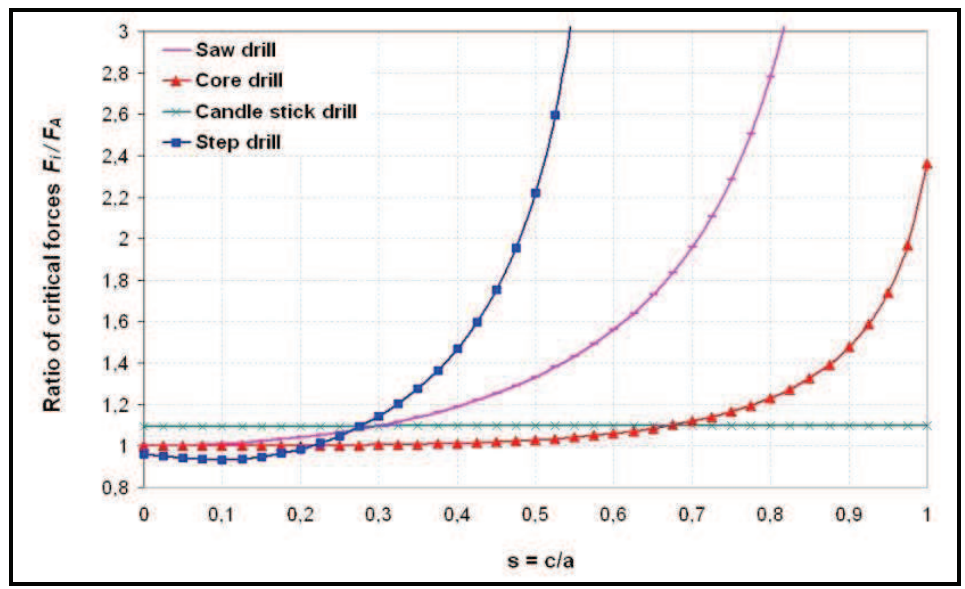

Figure 10 : Comparison of critical forces for different types of tools [8]

The influence of the central part of the tool on the thrust force can be explained by the cutting kinetics. Despite of the tool shape that lowers the ploughing effect at the center of the tool, the cutting speeds are low because of the rotating movement. The material of the workpiece is hence extruded rather than cut in this area. This implies the cracking initiations at the center when drilling with a conventional drill. The use of alternating tooth mill may be the solution to improve the drilling of composite materials without decreasing the hole quality. Furthermore, a comparative study also shows that the step drill is efficient concerning the size of defects on the surface of entry and exit. But this type of tool has not been tested in this study. 


\subsection{The reamers (tools 3 and 5)}

Unlike the drilling with mills or drills, the contouring operation creates a defect that does not depend on the feed rate (Figure 4). The reason is the geometry of the reamer that creates a uniform repartition of the thrust force, which is also lower because the central part of the hole has already been drilled in a first operation. The results shows that, for any feed rate tested, the thrust force never exceeded the critical value [8]. However, instead of the feed rate, the defect on the surface at the entry depends on the cutting speed. All of the reamers that have a positive helix angle peel off the first ply with a peeling force generated during the cutting of the first ply [5, 7]. That explains the influence of the cutting speed on the value of the peeling force.

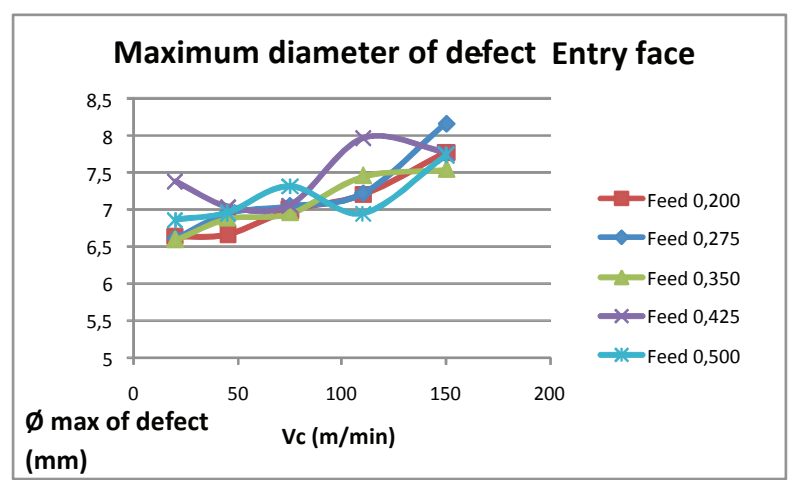

Figure 4 : Relations cutting condtions - diameter of defect (tool 5)

For the tool $3(\varnothing 4.8 \mathrm{~mm})$ only the lowest cutting conditions (Vc $20 \mathrm{~m} / \mathrm{min}$ and $\mathrm{f} 0.15 \mathrm{~mm} / \mathrm{rev}$ ) generates a size of defect below the chosen threshold. The tool $5(\varnothing 6.35 \mathrm{~mm})$, with the recommended cutting conditions produce a minimum defect reaching $0.24 \mathrm{~mm}$ over the contouring diameter. Only four cutting conditions limit the size of defects to $6.70 \mathrm{~mm}$ as required.

For those reamers, the influence of the cutting conditions on the surface roughness has been analyzed because it is a finishing operation. The criterion used is the mean surface roughness Ra measured, as explained before, on several lines, despite this criterion not being adapted to describe the wall of the drilled hole [12]. The results never exceed $1 \mu \mathrm{m}$ for the tested samples which have acceptable defects on the surfaces of entry and exit. The main defect to control is, as expected, the size of the peeling defect.

\section{Conclusions}

The aim of this study was to control the cutting conditions when drilling the carbon-based composite materials T700-M21 and T800-M21 for the aeronautical industry. The analysis suggests optimal cutting conditions for three types of tools (drill, mill, reamer), for thicknesses of the workpiece of 4 and $8 \mathrm{~mm}$ and for three diameters drilled of $4.8 \mathrm{~m}, 6.35 \mathrm{~mm}$ and $12.7 \mathrm{~mm}$. Contrary to metallic materials, it is difficult to define criteria to describe the surface quality of composites, especially when the diameter, the shape of the surface and the direction of the defect prevent from having a good visual appreciation.

For the drills, a strong decrease of cutting conditions provided by the tool manufacturers is necessary for a satisfactory quality. Drills are the most efficient solution concerning the time needed to drill a hole with an acceptable quality and should be chosen for a time optimization. For reamers, there is little scope for optimizing the machining conditions provided by the tool manufacturer. Concerning the helicoidal mill with three teeth, the first hole was acceptable with a new tool, but the tool wear is very important and defects would appear on the second hole drilled. The mills with alternating tooth profile give good results and allow the increase of the cutting speed and the feed rate without increasing the damages. When drilling composite materials, the mills with external tips have an excellent tool life compared to the other types which have a larger line contact with the wall (margin edge for the drill, cutting edges for the mills). Mills may be chosen to obtain the best quality before a finishing operation. 
The influence of tool wear was not supposed to be a part of this project. The paper only notes a linear tool-wear for some tools which can be related to cutting forces and size of defect. This could therefore be a way to establish a real-time control system. Tool wear mechanism differs for each type of tool. Reamers have little tool wear, and no consequence is visible on a few holes drilled. Drills have the most linear tool wear, after a first phase resembling running-in of metals. Mills may have catastrophic and rapid tool wear if the cutting conditions are not chosen carefully. Further study is needed about the importance and consequences of tool wear.

In perspective, it would also be interesting to test the step drills which may be more efficient concerning the defects on the hole surface.

\section{Acknowledgments}

This study has been done as part of the project R\&T EPICEA "Émergence de projets innovants composite portés par des entreprises aéronautiques" COMPO-USINAGE. Its objective is to control the cutting conditions of composite materials to produce aircraft reference parts. We would like to thank the Midi-Pyrénées region for its help and all the industrial partners: PMTL groupe NEXEYA (Cologne), NDT Expert (Toulouse) and SUD INGENIERIE (Colomiers).

\section{References}

[1] C. Garnier, M.L. Pastor, F. Eyma, B. Lorrain, « The detection of aeronautical defects in situ on composite structures using Non Destructive Testing », Composites Structures, Vol. 93, $\mathrm{n}^{\circ}$ 5, 13281336, Apr 2011.

[2] S. Abrate, D.A. Walton, "Machining of composite materials: Part I : Traditional methods", Composites Manufacturing, 3:75-83, 1992.

[3] P. Ghidossi, «Contribution à l'étude de l'effet des conditions d'usinage d'éprouvettes en composites à matrice polymère sur leur réponse mécanique ", Thèse de doctorat de l'Ecole Nationale Supérieure d'Arts et Métiers - Châlons en Champagne, 2003

[4] H. Hocheng, C.K.H. Dharan, Delamination during drilling in composite laminates, ASME Journal of Engineering Industry, vol.112, pp.236-239, 1990.

[5] R. Piquet, F. Lachaud, P. Dubourd, « Optimisation des conditions de contact outil/plaque dans le cadre de perçage de stratifiés minces en carbone / époxy », JNC 13, pp. 171-180, 2003

[6] C. C. Tsao, and H.Hocheng,"Taguchi Analysis of Delamination Associated with Various Drill Bit in Drilling of Composite Material", International Journal of Machine Tools \& Manufacture, Vol. 44, No.10, pp.1085-1090, 2004.

[7] P. Rahmé, Y. Landon, P. Lagarrigue, F. Lachaud, R. Piquet, « Study into causes of damage to carbon epoxy composite material during the drilling process », International Journal of Machining and Machinability of Materials, Vol. 3, No.3/4, p. 309-325, 2008.

[8] P.Rahmé, Y.Landon, P.Lagarrigue, F.Lachaud, R.Piquet, « Drilling thick composite materials using large diameter drills», International Journal of Machining and Machinability of Materials, vol.10, 202-221, 2011.

[9] L.M.P. Durão, D.J.S. Gonçalves, J.M.R.S. Tavares, V.H.C. de Albuquerque, A.Aguiar Vieira, A. Torres Marques, Drilling tool geometry evaluation for reinforced composite laminates, Composite Structures, Volume 92, 2010, Pages 1545-1550.

[10] W. König, Ch. Wulf, P. Graß, H. Willerscheid, Machining of Fibre Reinforced Plastics, CIRP Annals - Manufacturing Technology, Volume 34, Issue 2, 1985, Pages 537-548.

[11] B. Furet, B. Jolivel, D. Le Borgne, Milling and drilling of composite materials for the aeronautics, International review JEC Composites, vol.18, pp.41-44, 2005.

[12] W. König and P. Grass, «Quality definition and assessment in drilling of fiber reinforced thermosets », Annals of the C.I.R.P $n^{\circ} 38$, p. 119-124, 1989.

[13] R. Zitoune, F. Collombet, R. Piquet, F. Lachaud, P. Pasquet, " Experiment-calculation comparison of the cutting conditions representative of the long fiber composite drilling phase ", Composites Science and Technology, vol. 65, n³-4, p. 455-466, 2005. 